\title{
Environmental costing research based on a CiteSpace analysis
}

\author{
WU Jia ${ }^{1, \mathrm{a}}$, GONG Zhiqi *2,b \\ ${ }^{1}$ School of Civil Engineering, Qinghai University Qinghai Pro-vincial Key Laboratory of Energy-saving Building Materials and \\ Engineering Safety Xining, Qinghai, China \\ ${ }^{2}$ School of Civil Engineering, Qinghai University Qinghai Provincial Key Laboratory of Energy-saving Building Materials and Engine- \\ ering Safety Xining, Qinghai, China
}

\begin{abstract}
Taking Scopus database as data source, CiteSpace was used to construct knowledge map of environmental cost accounting research, and the current research hotspots and future research trends in this field were analyzed. According to the research results, relevant suggestions are put forward to provide reference for the development of environmental cost accounting research.
\end{abstract}

\section{Introduction}

After the reform and opening up, my country's economy has developed rapidly. However, what followed is the destruction of the environment. The phenomenon of "sacrificing the environment in exchange for economic growth" has become more and more serious, and even threatened the survival of mankind. The government has issued a series of policies calling on people to protect the environment. Scholars in various fields also responded positively and conducted a large number of studies on various aspects of the environment. Among them, WenHsien Tsai et al. (2010) proposed to combine activitybased costing with environmental cost accounting to make managers' decisions more accurate and objective ${ }^{[1]}$,WenHsien Tsai et al. (2012) strongly proved that the activitybased costing method is very effective in identifying the environmental cost of the final product. ${ }^{[2]}$, Chunbo Zhang et al. (2020) Through case studies, the advantages and disadvantages of internalization of external costs and how to make better use of the economic feasibility and environmental soundness of PCE are determined ${ }^{[3]}$.

\section{Research tools and data sources}

\subsection{Introduction to Research Tools}

The main research tool used in this article is CiteSpace. CiteSpace is a scientific and technological text data visualization software developed by Professor Chen Chaomei. It draws a network map of author cooperation, a network of publishing organizations, a map of cooperation of publishing countries, a map of keyword clustering, and Timeline diagrams, etc. to further analyze the cooperative relationship between various research fields, so as to analyze the development path of its research and current research hotspots in a deeper level, and then predict the future development direction of the research ${ }^{[4]}$.

\subsection{Data source and processing}

The data in this study are all from Scopus database. The retrieval method is to set the time span from 2010 to 2020 , and take "environmental costing" OR "external costing" as the keyword for retrieval. At the same time, Conference Paper, Book Chapter and Editorial literature are excluded, and only article literature is retained, and 833 valid literatures are finally obtained. The literature after retrieval and screening is used as the main basis for knowledge graph analysis of environmental cost accounting research, so as to make visual analysis.

\section{The spatiotemporal knowledge map of environmental costing}

\subsection{Paper volume analysis}

Statistical methods were used to make a visual analysis of the final retrieval results of Scopus database related to environmental cost accounting, and the annual distribution map of publication volume was obtained as shown in Figure 1. As can be seen from the figure, the number of published papers increased almost linearly from 2010 to 2020 , and reached a peak in 2020. This indicates that the research on environmental cost accounting has increasingly become the focus of scholars, and the results are quite rich. 


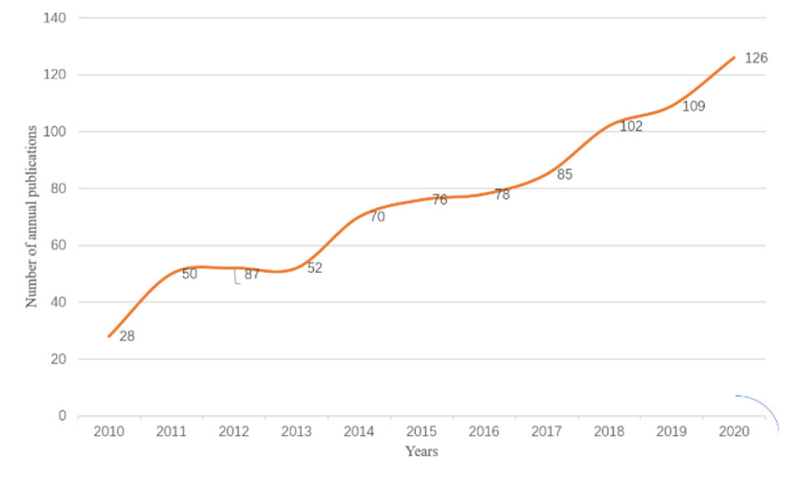

Fig 1. The number of articles published in the past decade

\subsection{Author analysis}

In CiteSpace node type is set to the author, the time span of 2010 to 2020 , the time slice is set to 1 year, after running to the post author collaboration network map is shown in figure 2, the map shows the node number is 331 , in the attachment number is 183 , density is 0.0034 , which can be concluded that the relationship between the author and the various articles is a little loose. At the same time, it can be seen from the figure that the cooperation is mostly between 2-3 people, and only a few authors have formed some research cooperation groups. However, as the accounting of environmental cost is distributed in various fields, the cooperation among the authors is relatively weak.

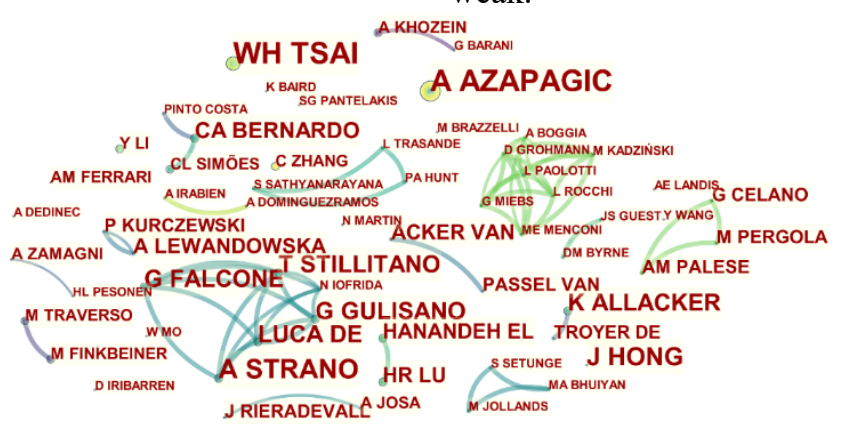

Fig 2. Cooperation networks for auther

\subsection{Analysis by the issuing agency}

The same method was used to analyze the cooperation network of publishing institutions, and the cooperation graph of publishing institutions' network, as shown in Figure 3, was obtained. The number of nodes was 324, the number of connections was 218 and the density was 0.0042 . The number of nodes and the number of connections are relatively large, indicating that from 2010 to 2020, the research related to environmental cost accounting in China has become more and more mature. In addition, it can be seen from the figure that there are few connections between institutions, indicating that the cooperation among institutions is relatively loose. Secondly, the size of nodes represents the number of papers issued by institutions. It can be seen that most of the top 10 institutions issued papers are foreign universities, which indicates that China currently lacks research on environmental cost accounting related content.

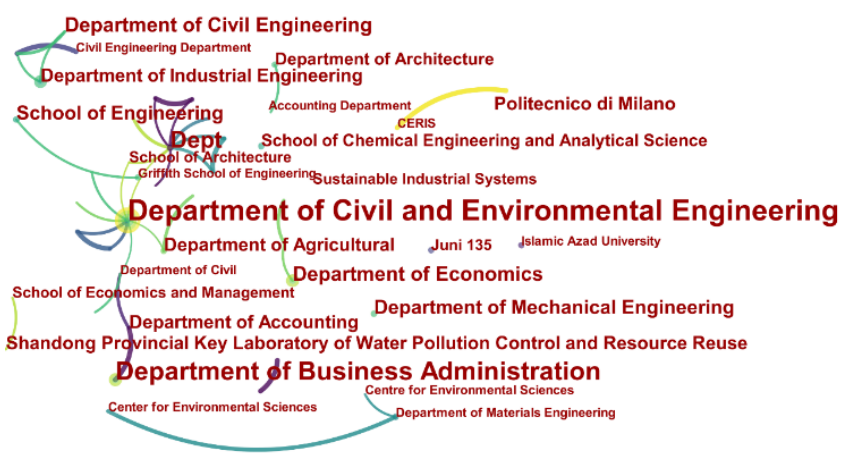

Fig 3. Cooperation networks for institutions

\subsection{High frequency keyword analysis}

Through the analysis of high-frequency keywords, we can understand the core ideas and research contents of the research field, so as to further analyze the research hotspots ${ }^{[5]}$. For a long time, the general problem of 
environmental cost accounting has focused on the recognition and measurement of cost, which is also the key of accounting. The research content in this aspect is also the most, and the cost recognition and measurement are mostly considered from the life cycle. The table 1 shows that the top three most of them are related to the "life cycle", the accounting of environment cost is mostly associated with the life cycle, whether from the perspective of life cycle in this paper, the environmental cost accounting system, or using the method of life cycle cost of environmental cost accounting, are scholars research hot spot problems.

Table1. Research on high frequency keywords

\begin{tabular}{|c|c|c|c|}
\hline Count & Keywords & Count & Keywords \\
\hline 276 & life cycle & 208 & environmental impact \\
\hline 265 & cost & 194 & $\begin{array}{c}\text { life cycle assessment } \\
\text { (lca) }\end{array}$ \\
\hline 252 & life cycle costing & 171 & cost benefit analysis \\
\hline 249 & $\begin{array}{c}\text { life cycle } \\
\text { assessment }\end{array}$ & 166 & $\begin{array}{c}\text { sustainable } \\
\text { development }\end{array}$ \\
\hline 213 & article & 143 & life cycle analysis \\
\hline
\end{tabular}

\section{Frontier evolution of environmental cost accounting research}

The research frontier can enable scholars to understand the general research direction of the current research field, so as to further explore the research content. In this paper, CiteSpaces keyword emergence combined with the corresponding literature is used for further analysis to explore the frontier issues concerned by the environmental costing research institute and their evolution trend.

Table2. Top 15 Keywords with the Strongest Citation Bursts

\begin{tabular}{|c|c|c|}
\hline Keywords & Strength & $2010-2020$ \\
\hline cost benefit analysis & 5.05 & 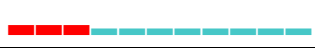 \\
\hline activity based costing system & 3.75 & - \\
\hline $\begin{array}{c}\text { life cycle sustainability } \\
\text { assessment }\end{array}$ & 5.22 & - \\
\hline methodology & 4.75 & 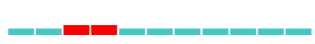 \\
\hline optimization & 3.65 & 2- \\
\hline energy resource & 3.36 & 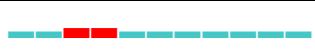 \\
\hline life cycle thinking & 5.6 & 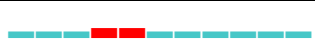 \\
\hline $\begin{array}{l}\text { environmental aspects and } \\
\text { related phenomena }\end{array}$ & 5.14 & - \\
\hline environmental factor & 3.52 & 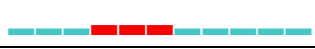 \\
\hline model & 3.42 & -2 \\
\hline water treatment & 4.06 & 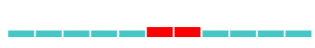 \\
\hline statistics and numerical data & 3.41 & 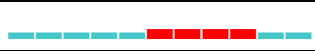 \\
\hline manufacture & 3.45 & 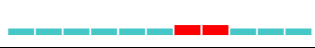 \\
\hline major clinical study & 3.56 & 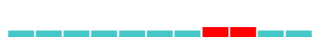 \\
\hline waste incineration & 3.58 & عاسم \\
\hline
\end{tabular}

\subsection{Advance research frontier}

The early stage of the research has emerged from 2010 to
2015. The research frontier of environmental cost accounting in this stage mainly focuses on "cost benefit analysis", "activity based costing system" and "life cycle sustainability assessment men". In December 2011, the State Council issued the Twelfth Five-Year Plan for Environmental Protection, which has enhanced the enthusiasm of the public in environmental protection. During this period, most scholars focused on environmental cost accounting methods, most of which were combined with activity-based costing and life cycle costing. In addition, there were also combined with complete costing and variable costing. The concrete idea is to introduce the generalized cost accounting method into the environmental cost accounting, and combine the characteristics of the environmental cost itself to flexibly apply these methods.

\subsection{Frontiers of Recent Research}

Recent studies have appeared from 2015 to 2020. Frontiers of environmental cost accounting research at this stage mainly focus on "water treatment", "statistics and numerical data", "manufacture", and "waste cineration". In 2016, the Ministry of Environmental Protection released a series of environmental protection policies and regulations Such as released in November 2016, "environmental protection" much starker choices-and graver consequences-in planning basic train of thought ", issued by the ministry in April 2017, the state environmental protection standards "much starker choices-and graver consequences-in" development plan ", as well as the general office of the central committee of the communist party of China in March, 2020, issued by The General Office of the State Council "about building the guidance of modern environmental management system", and issued a circular, urged all localities departments combined with real earnest implementation, etc., these policies are the environmental costs of the related research to the peak. Combined with the analysis of related emergent words, it can be seen that the environmental problems in recent years are mainly reflected in water pollution, environmental pollution caused by the development of manufacturing industry and waste incineration, etc.

\section{Conclusions}

This paper uses CiteSpace visualization software to analyze the environmental cost accounting research of 833 core journals from 2010 to 2020 based on Scopus database. It is concluded that in the past ten years, the research results of environmental cost accounting have been increasing, but the authors and institutions of environmental cost accounting lack close cooperation. The hot research fields of environmental cost accounting include "life cycle", "life cycle costing" and "environmental impact". The latest research frontier is "water treatment", "statistics and numerical data", "manufacture", and "waste cineration". Based on the above conclusions, this paper puts forward the following suggestions: 
Cooperation between authors and agencies should be strengthened. At present only a few authors formed some research collaboration between groups, because of the complexity of the field, has led to the relationship between the author and weaker, so for existing partnership should deepen cooperation between the author, with no relationship between the author, should establish cooperation relations, so as to jointly promote the boast skillful development in the field of environmental cost accounting research.

Study the hot topics from different perspectives. At present, the key of environmental cost accounting is the confirmation and calculation of the cost, which is also a major difficulty. Therefore, in view of this problem, each author or research group should analyze the environmental cost from multiple perspectives, so as to make the research results more accurate and effective.

To improve the method of environmental cost accounting and promote the development and innovation of this research field. There are some limitations in environmental cost accounting methods and they lack wide applicability. In the future, with the advancement of related research and the continuous introduction of environmental policies, the research results in the field of environmental costing research will become more and more abundant.

\section{References}

1. Tsai,W.H., Lin, T.W., Chou, W.C. (2010) Integrating activity-based costing and environmental cost accounting systems: A case study, Int. J. Bus. Syst. Res., 4:186-208.

2. Tsai, W.H., Shen, Y.S., Lee, P.L. Chen, H.C., Kuo,L., Huang, C.C. (2012) Integrating information about the cost of carbon through activity-based costing, Journal of Cleaner Production., 36: 102-111.

3. Zhang, C., Hu, M., Yang, X., Amati, A., Tukker,A. (2020) Life cycle greenhouse gas emission and cost analysis of prefabricated concrete building façade elements, J. Ind. Ecol., 24:1016-1030.

4. Chen,Y., Chen,C.M., Liu,Z.Y., Hu,Z.G.,Wang,X.W. (2015) Methodological Functions of CiteSpace Knowledge Graph. J. Scientific research., 33: 242253.

5. Hu, J.P., Lin,L.J. (2019) Hot Topics and Frontier Evolution of Disability Research in China: Visual Analysis Based on CSSCI Journals, J. Shandong Social Sciences., 11: 118-125. 